\title{
Cognitive Stimulation in Patients with Dementia: Randomized Controlled Trial
}

\author{
Daniela Mapellia Elisa Di Rosa ${ }^{a}$ Rosaria Nocitab Donatella Sava ${ }^{b}$ \\ a Department of General Psychology, University of Padua, Padua, and ${ }^{\mathrm{b}}$ Centro Servizi \\ per Anziani, Monselice, Italy
}

\author{
Key Words \\ Nonpharmacological therapies - Cognitive stimulation treatment · Behavioral and \\ psychological symptoms of dementia
}

\begin{abstract}
Background/Aims: This study explores the effective outcomes of a structured cognitive stimulation treatment to improve cognition and behavioral symptoms in people with dementia (PWDs), using a randomized controlled clinical trial. Methods: Thirty PWDs were divided into three groups: experimental (treated with cognitive stimulation), placebo (treated with occupational therapy), and control (continuing with the usual activities of the nursing home). Assessment, at baseline and after a period of 8 weeks, was performed using the Clinical Dementia Rating Scale, activities of daily living, Mini-Mental State Examination, Esame Neuropsicologico Breve 2, Geriatric Depression Scale and Behavioral Pathology in Alzheimer's Disease Scale. Results: Only the experimental group improved its performance in cognitive tests $(p<0.05)$ and showed a significant decrease in behavioral symptoms $(p<0.01)$ after the treatment. Conclusions: The results suggest that a cognitive stimulation treatment for PWDs would improve not only their cognition, but also behavioral symptoms.
\end{abstract}

(C) 2013 S. Karger AG, Basel

\section{Introduction}

The increasing prevalence of dementia as a public health problem results from the rapid aging of the population. That dementia remains incurable is aggravating this situation. The current limits of the effectiveness of pharmacotherapies highlight the value and the significant role of nonpharmacological interventions in delaying the progression of the disease and the functional decline. The class of nonpharmacological therapies includes cognitive stimulation 
treatment. Cognitive stimulation typically involves a set of tasks designed to reflect cognitive functions such as attention, memory, language, and problem solving, combined with a reality orientation session. This training takes place in individual or group sessions with a range of difficulty levels. The fundamental assumption is that practice with specific cognitive function tasks may improve, or at least maintain, functioning in a given domain and that any effects of practice will generalize and induce a general improvement of cognitive and social functioning.

Recent reviews of cognitive stimulation [1,2] conclude that its effects on cognition, communication, social interaction, well-being, and quality of life are well documented. In contrast, in the Cochrane review [1], the authors maintain that there are no indications that cognitive stimulation is associated with changes in mood or behavior and that there is much less evidence available regarding these domains compared with that available for changes in cognition.

Behavioral and psychological symptoms of dementia represent a very frequent problem that undermines the quality of life of people with dementia (PWDs) and produces psychological and financial encumbrances for their caregivers. Many dementia practice guidelines recommend nonpharmacological measures as the main treatment for behavioral and psychological symptoms of dementia [3-5], and recent studies report the effectiveness of nonpharmacological interventions for improving the quality of life of PWDs [6, 7].

There is a lot of evidence for the effectiveness of the nonpharmacological therapies in improving cognition [8-14], behavior [15-18], mood [19-21], and activities of daily living [22], in delaying institutionalization [23], and in improving the quality of life of patients and caregivers [6, 24]. A recent systematic review [25] reports, regarding the positive outcomes of nonpharmacological therapies, that the best evidence base is for cognitive stimulation treatment, although this approach is labor-intensive, and requires further evaluations of costeffectiveness. However, even after many studies and other evidence, the evaluation of the effectiveness of the cognitive stimulation treatment remains uncertain because some methodological issues often make the interpretation of the research data problematic and because it requires further evaluation of its cost-effectiveness.

In many studies, the main limitation is represented by the definition of a control group or a condition essential for the evaluation of a therapy's effectiveness. Whereas the use of usual care or minimal attention conditions for the control group can lead to positive results, intervention specificity becomes unclear when the experimental and control groups are exposed to similar social attention [26]. In the recent literature, there is not a clear theoretical model with a definite agent intended to result in a specific outcome, and the number of highquality randomized controlled trials remains low [13].

For these reasons, this study aims to investigate the effects of a structured cognitive stimulation treatment on improving cognition and activities of daily living in PWDs by a comparison between a placebo and a control group and to explore the differences between mild and moderate dementia. In addition, this paper intends to investigate the effects of the cognitive stimulation treatment on behavioral and psychological symptoms of dementia, assuming the key role of cognitive deficits in the development of disruptive and challenging behaviors.

\section{Materials and Methods}

\section{Participants}

A total of 180 participants were recruited at the nursing home, Centro Servizi per Anziani, in Monselice (Padua), Italy. They were evaluated for their eligibility by the neurologist and neuropsychologist of the Centro Servizi per Anziani. Inclusion criteria included subjects at stage 1 or 2 on the Clinical Dementia Rating Scale (CDR) [27] and with a Mini-Mental State 


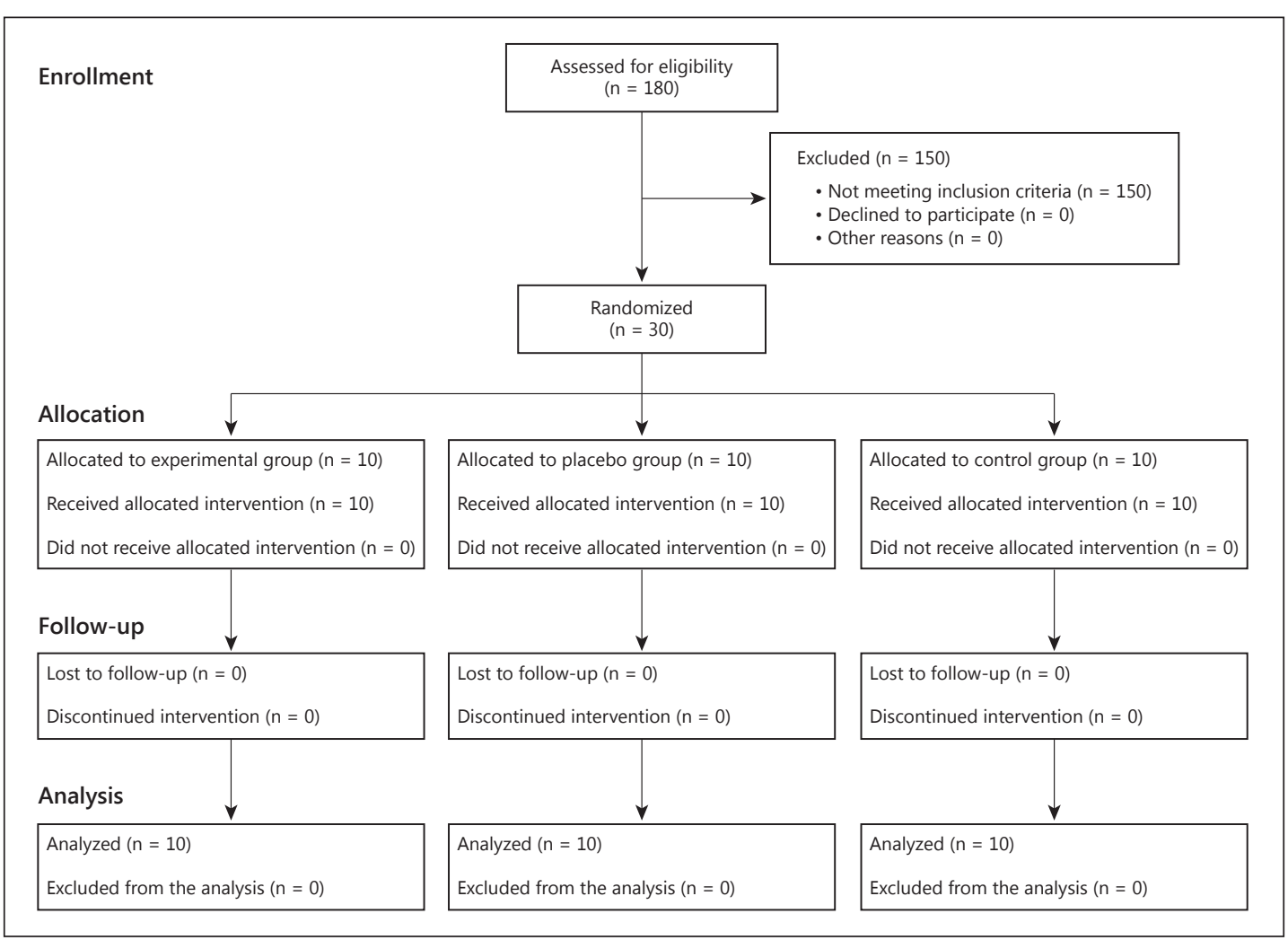

Fig. 1. Flow diagram of the randomized controlled trial.

Examination (MMSE) [28] score of 14-24. They were able to communicate and understand verbal and written language and physically able to participate in a meaningful assessment and a rehabilitation program. Subjects who suffered from a learning disability or psychiatric or internal disorders, such as schizophrenia or alcoholism, were excluded. Taking these inclusion criteria into account, 30 participants were enrolled: 16 with a diagnosis of Alzheimer's disease, 13 with vascular dementia, and 1 with mixed dementia, according to DSM-IV-TR criteria [29].

Participants were randomized into three groups, i.e. experimental, placebo, and control groups, following a simple computerized randomization technique (fig. 1). In each group, there were 5 patients with mild dementia, who scored 19-24 on the MMSE and 1 on the CDR, and 5 patients with moderate dementia, who scored 14-18 on the MMSE and 2 on the CDR.

The experimental, placebo, and control groups did not differ in terms of age, years of education, and MMSE score ( $p>0.05$ ) (table 1). The study was approved by the local ethics committees, and written informed consent was obtained from the patients and/or their family caregivers.

\section{Assessment/Outcome Measures}

To provide a global rating of dementia severity, the CDR [27] was used. This is a 5-point scale $(0=$ no dementia; $0.5=$ possible dementia; 1 = mild dementia; 2 = moderate dementia; 3 = severe dementia) completed by the researcher. Cognitive functions were evaluated using the MMSE [28] and Esame Neuropsicologico Breve 2 (ENB2) [30], a neuropsychological battery that includes 14 subtests: digit span, immediate and delayed recall prose memory, 
Table 1. Demographic characteristics and test scores before (pre) and after (post) the 8 weeks' treatment, with significant interaction using the Fisher post hoc test (mean \pm SD)

\begin{tabular}{|c|c|c|c|c|c|c|}
\hline & \multicolumn{2}{|c|}{ Experimental group } & \multicolumn{2}{|c|}{ Placebo group } & \multicolumn{2}{|c|}{ Control group } \\
\hline & $\begin{array}{l}\text { pre } \\
(\mathrm{n}=10)\end{array}$ & $\begin{array}{l}\text { post } \\
(n=10)\end{array}$ & $\begin{array}{l}\text { pre } \\
(\mathrm{n}=10)\end{array}$ & $\begin{array}{l}\text { post } \\
(\mathrm{n}=10)\end{array}$ & $\begin{array}{l}\text { pre } \\
(\mathrm{n}=10)\end{array}$ & $\begin{array}{l}\text { post } \\
(\mathrm{n}=10)\end{array}$ \\
\hline Age, years & $82.6 \pm 4.85$ & & $84.5 \pm 5.06$ & & $84.7 \pm 4.42$ & \\
\hline Education, years & $4.6 \pm 1.5$ & & $4.3 \pm 1.82$ & & $4 \pm 1.15$ & \\
\hline \multicolumn{7}{|l|}{ Cognition } \\
\hline CDR & $1.5 \pm 0.052$ & $1.25 \pm 0.54^{1}$ & $1.5 \pm 0.52$ & $1.6 \pm 0.51^{2}$ & $1.5 \pm 0.52$ & $1.5 \pm 0.52^{2}$ \\
\hline MMSE & $20.1 \pm 4.2$ & $23 \pm 2.76$ & $19.7 \pm 3.8$ & $18.2 \pm 2.71^{2}$ & $18.8 \pm 2.68^{2}$ & $18.5 \pm 2.73^{2}$ \\
\hline \multicolumn{7}{|l|}{ ENB2 } \\
\hline IRPM & $4.6 \pm 2.2$ & $7.2 \pm 3.7^{1}$ & $3.4 \pm 2.2$ & $2.9 \pm 1.85^{2}$ & $4.9 \pm 2.6$ & $4.2 \pm 2.34^{2}$ \\
\hline DRPM & $3.8 \pm 2.9$ & $8 \pm 3.9^{1}$ & $2.7 \pm 1.4$ & $2.2 \pm 2.28^{2}$ & $3.7 \pm 2.4$ & $2.9 \pm 2.28^{2}$ \\
\hline BPT $10 \mathrm{~s}$ & $1.1 \pm 2.02$ & $2.8 \pm 1.9^{1}$ & $2.2 \pm 2.09$ & $2.1 \pm 1.96$ & $0.9 \pm 1.28$ & $1 \pm 1.15^{2}$ \\
\hline WPF & $3.4 \pm 2.52$ & $4.6 \pm 2.05^{1}$ & $3.17 \pm 1.5$ & $3.4 \pm 2.16$ & $3.64 \pm 1.86$ & $3 \pm 1.5$ \\
\hline Abstraction & $1.1 \pm 0.87$ & $3.4 \pm 0.7^{1}$ & $1.6 \pm 1.5$ & $1.1 \pm 1.28^{2}$ & $1 \pm 1.15$ & $0.8 \pm 1.3^{2}$ \\
\hline CDT & $2.7 \pm 2.66$ & $6.15 \pm 3.07^{1}$ & $3.45 \pm 2.8$ & $2.25 \pm 2.48^{2}$ & $2.7 \pm 2$ & $1.3 \pm 1.15^{2}$ \\
\hline ENB2.tot & $34.8 \pm 5.8$ & $43.5 \pm 9.2^{1}$ & $35.4 \pm 7.4$ & $33.9 \pm 8.1^{2}$ & $33.6 \pm 8.6$ & $31.4 \pm 5.5^{2}$ \\
\hline \multicolumn{7}{|l|}{ Behavior } \\
\hline Behave-AD & & & & & & \\
\hline symptoms & $7.7 \pm 8.04$ & $0.5 \pm 0.5^{1}$ & $12.2 \pm 9.6$ & $11.1 \pm 7.43^{2}$ & $5.9 \pm 4.62$ & $8.4 \pm 3.9^{2}$ \\
\hline
\end{tabular}

IRPM = Immediate recall prose memory; DRPM = delayed recall prose memory; BPT = Brown-Peterson technique; $\mathrm{WPF}=$ word phonemic fluency; CDT = clock drawing test; ENB2.tot = ENB2 total score.

${ }^{1}$ Significant difference within the experimental group (Fisher post hoc test with Bonferroni correction for multiple comparisons; $\mathrm{p}<0.05$ ).

${ }^{2}$ Significant difference between the experimental group and the other two groups at post-treatment evaluation (Fisher post hoc test with Bonferroni correction for multiple comparisons; $\mathrm{p}<0.05$ ).

Brown Peterson technique, Trail Making Test parts A and B, token test (5 items), word phonemic fluency, abstraction, cognitive estimation test, intricate figures test, house figure copy, daisy drawing test, clock drawing test, and ideomotor apraxia test. All ENB2 subtests were measured in the traditional way, but only the Trail Making Test score was considered as the correct number of responses instead of time of execution. An ENB2 total score was calculated to obtain a general measure of the cognitive status [30]. As a measure of the functional status of the patients, the activity of daily living scale was used [31], completed by the caregivers and investigating personal daily care, with a score from 0 to 6 . The Behavioral Pathology in Alzheimer's Disease Rating Scale (Behave-AD scale) [32] was used to assess the frequency of problem behaviors during dementia (Behave-AD symptoms) and their impact on the caregiver (Behave-AD global) in the previous 2 weeks. The first part of this instrument measures 25 behavioral symptoms, grouped into 7 categories; each symptom was scored, regarding its severity, on 4 -point scales, and the total symptom score was from 0 (normal) to 75. The second part of the instrument consists of a single question for the caregiver that provides a total global score from 0 (no stress) to 3. Finally, to screen and rate geriatric depression, the Geriatric Depression Scale was used [33], which is a self-report questionnaire giving a global scoring from 0 to 30 . All these tests and scales were administrated in the three groups at baseline at the beginning and 8 weeks later. The three groups were evaluated by a blinded rater, who did not know the group allocation of the participants. The rater was not the same person who conducted the intervention treatments. 


\section{Intervention}

After a formal assessment, the participants were randomly allocated into experimental, placebo, and control groups, each composed of 10 patients. The experimental and the placebo groups received 8 weeks of intervention: cognitive stimulation treatment for the experimental group and occupational therapy for the placebo group. Both groups were involved in a 40 -session program that ran daily over 8 weeks, for $1 \mathrm{~h}$ per session or $5 \mathrm{~h}$ weekly. The control group participants continued with the usual activities program at the nursing home while the group therapies were in progress.

The cognitive stimulation treatment started with initial personal, spatial, and temporal orientation sessions and proceeded with a structured stimulation for the cognitive domain, consisting in individual exercises [34], specific for 5 areas (memory, language, spatial and temporal orientation, attention, and logic) and grouped into 3 levels of difficulty.

The therapist administered 2 or 3 cognitive paper/pencil exercises in the subgroup with mild dementia and 1 or 2 exercises in the subgroup with moderate dementia. The daily exercises were selected for each cognitive domain and the range of cognitive exercises was fixed weekly, starting with a low level of difficulty and becoming progressively more difficult. Therefore, the same number of paper/pencil exercises for each cognitive domain was selected, stimulating all cognitive functions in a balanced way. Finally, the mild dementia subgroup performed 70 exercises, while the moderate dementia subgroup performed 54 exercises, excluding the logic domain exercises, as the participants were not capable of performing them.

The placebo group daily performed a series of programmed activities: read and debate the newspaper, play bingo, sing, and take part in PET therapy, psychomotor stimulation and creative workshops. The activities were changed every day and were adapted according to the degree of dementia.

\section{Statistics}

Baseline demographic and clinical characteristics between the three groups were compared with a Fisher test. Post-intervention differences in the outcome measures between the three groups were evaluated with a three-way repeated-measures analysis of variance. The analysis of variance included 'group' (experimental vs. placebo vs. control) and 'stage of dementia' (mild vs. moderate) as between-subject factors and 'time' (pre vs. post) as the within-subject factor. We performed post hoc paired comparisons using a Fisher test, and Bonferroni correction for multiple comparisons was also applied. Statistical significance refers to a $\mathrm{p}$ value of $<0.05$.

\section{Results}

Analysis of variance did not show any significant interaction between the stage of dementia (mild vs. moderate), time (pre vs. post), and group (experimental, placebo, and control). So, we reported the results without considering the stage of dementia.

The results revealed significant differences among the three groups at the post-treatment evaluations and between the experimental group's baseline evaluation and its post-treatment evaluation (table 1). A significant interaction between 'time' and 'group' factors in CDR score analyses $\left[F(2,24)=3.267 ; p<0.05\right.$, partial $\left.\eta^{2}=0.21\right]$ showed that after 8 weeks, only the patients in the experimental group exhibited an improvement in terms of a decrease in dementia severity: the mean score on the CDR scale decreased significantly $(p<0.05)$, while that of the other two groups remained stable (fig. 2). 
Fig. 2. Mean CDR scores before and after the treatments for the three groups. * = Significant score decrease only in the experimental group.

Fig. 3. Mean MMSE scores before and after the treatments for the three groups. ${ }^{*}=$ Significant difference between pre- and posttreatment scores only in the experimental group.
Mapelli et al.: Cognitive Stimulation in Patients with Dementia: Randomized Controlled Trial
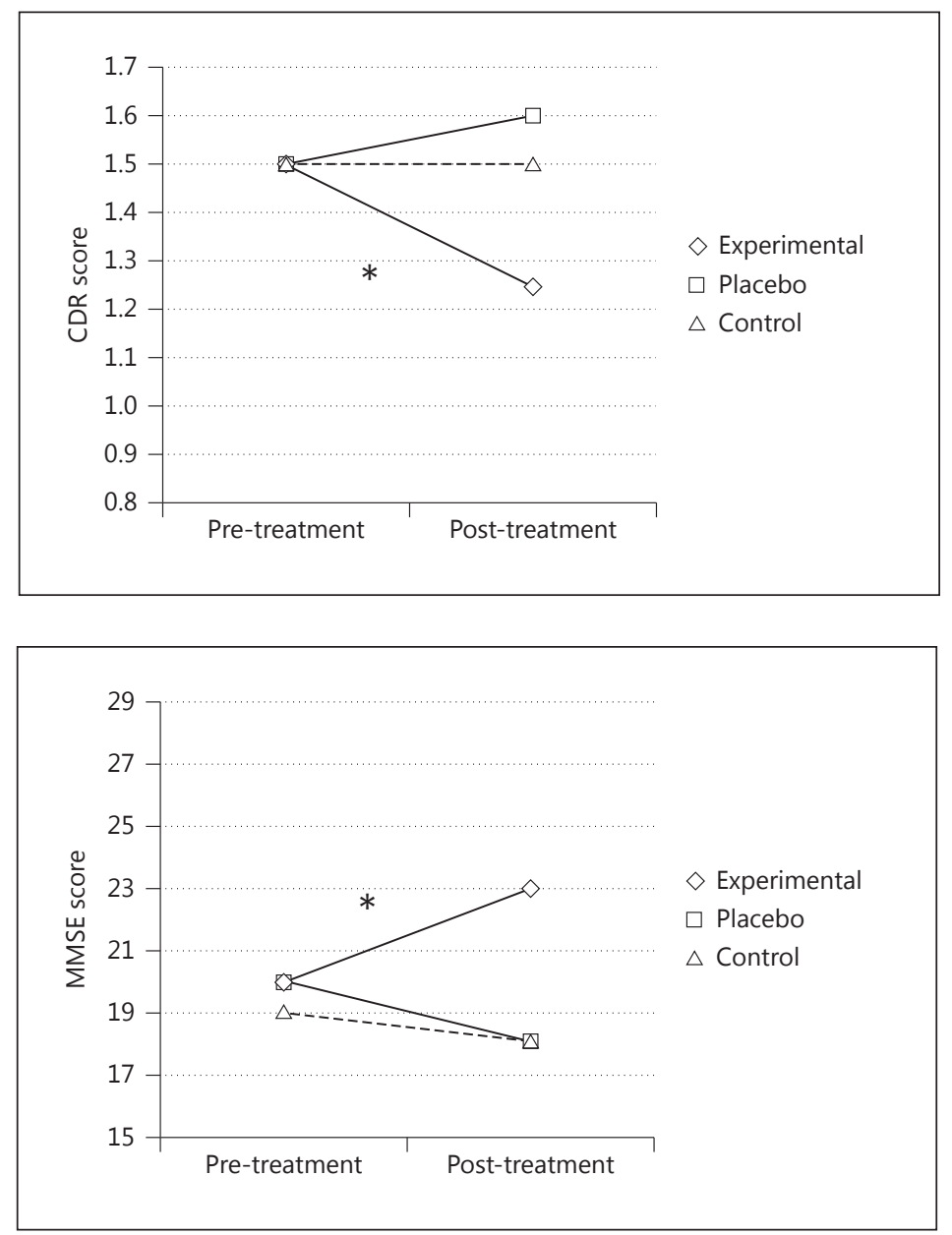

After the treatment, the experimental group had significantly better performances on the MMSE $\left[F(2,24)=11.57 ; p<0.001\right.$, partial $\left.\eta^{2}=0.49\right]$ (fig. 3) and in the following ENB2 subtests: immediate recall prose memory $\left[\mathrm{F}(2,24)=4.92 ; \mathrm{p}<0.05\right.$, partial $\left.\eta^{2}=0.29\right]$, delayed recall prose memory $\left[\mathrm{F}(2,24)=7.58 ; \mathrm{p}<0.05\right.$, partial $\left.\eta^{2}=0.38\right]$, clock drawing test $[\mathrm{F}(2,24)=$ 15.15; $p<0.001$, partial $\left.\eta^{2}=0.55\right]$ and abstraction $\left[F(2,24)=8.91 ; p<0.05\right.$, partial $\left.\eta^{2}=0.42\right]$, and ENB2 total score $\left[F(2,24)=14.06 ; p<0.001\right.$, partial $\left.\eta^{2}=0.54\right]$ (fig. 4). The other two groups did not show any significant changes.

Moreover, after 8 weeks of treatment, the experimental group displayed a significant decrease of behavioral symptoms, while the placebo and the control groups did not show significant changes $\left[F(2,24)=5.95 ; p<0.005\right.$, partial $\left.\eta^{2}=0.33\right]$ (fig. 5).

\section{Discussion}

The aim of this study was to explore the efficacy of cognitive stimulation treatment in patients with mild and moderate dementia. The findings of this study show that 40 sessions (8 weeks) of cognitive stimulation treatment resulted in a significant improvement of cognitive and behavioral symptoms in patients with mild and moderate dementia. After 8 weeks of cognitive stimulation treatment, the patients showed a significant decrease in 
Fig. 4. Mean ENB2 total scores before and after the treatments for the three groups. ${ }^{*}=$ Significant difference between pre- and post-treatment scores only in the experimental group.

Fig. 5. Mean Behave-AD symptom scores before and after the treatments for the three groups. ${ }^{*}=$ Significant difference between pre- and post-treatment scores only in the experimental group.
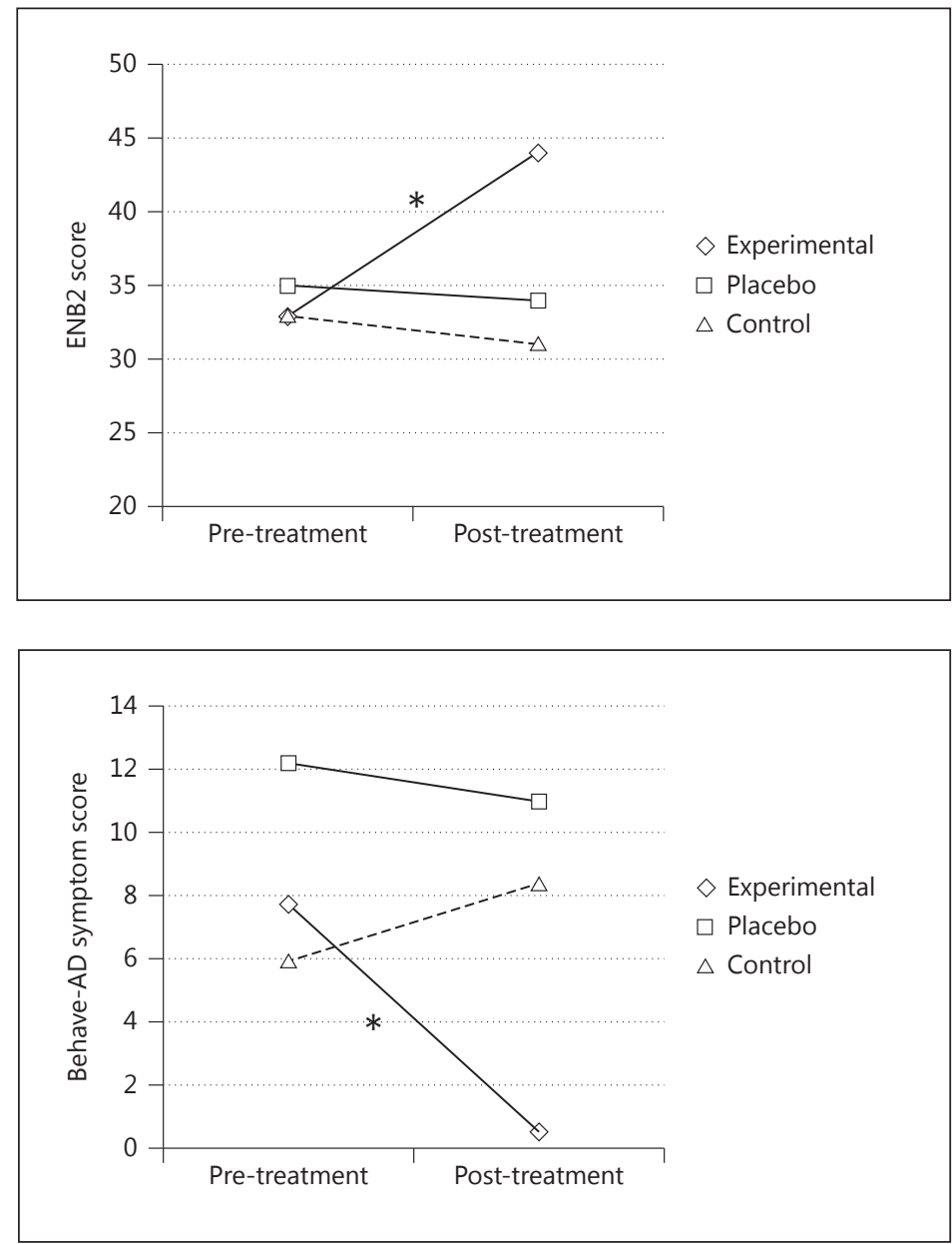

dementia severity, a better performance in memory, abstraction, planning, and visuospatial ability, and a significant decrease in behavioral symptoms. The findings of this study provide additional evidence for the effectiveness of cognitive stimulation treatment, recently well documented [1, 2, 35]. Furthermore, these results highlight the specificity of the cognitive stimulation treatment efficacy because PWDs treated with cognitive stimulation were compared with placebo and control conditions. In the placebo group, patients with mild and moderate dementia were treated with an occupational therapy program and patients in the control group followed the usual activities of their nursing home.

The presence of a significant improvement only for the experimental group helps the data interpretation in terms of intervention specificity because when the experimental and control groups were exposed to similar social attention, the positive results of the studies were less frequent, and intervention specificity became blurred [26]. In this study, the presence of a placebo group that did not show any significant improvement afterwards is strong evidence of the specificity of the cognitive stimulation treatment efficacy.

The positive results of this study also highlight the beneficial effects of cognitive stimulation treatment on behavioral symptoms, thereby supporting the findings that showed a correlation between cognitive impairment and behavioral symptoms in dementia [36-38] and supported the hypothesis that argues for a potential cognitive basis of behavioral symptoms. 
Mapelli et al.: Cognitive Stimulation in Patients with Dementia:

Randomized Controlled Trial

\section{References}

1 Woods B, Aguirre E, Spector AE, Orrell M: Cognitive stimulation to improve cognitive functioning in people with dementia (Review). Cochrane Database Syst Rev 2012;2:CD005562.

-2 Aguirre E, Woods RT, Spector A, Orrel M: Cognitive stimulation for dementia: a systematic review of the evidence of effectiveness from randomized controlled trials. Ageing Res Rev 2013;12:253-262.

3 The British Psychological Society and The Royal College of Psychiatrists: Dementia: A NICE-SCIE Guideline on Supporting People with Dementia and Their Carers in Health and Social Care. Leicester, British Psychological Society, 2007.

4 Singapore Ministry of Health: MOH Clinical Guidelines 5/2001: Dementia. Singapore, Singapore Ministry of Health, 2007.

5 Burns A, Iliffe S: Dementia. BMJ 2009;338:405-409.

6 Cooper C, Mukadam N, Katona C, Lyketsos CG, Ames D, Rabins P, Engedal K, de Mendonça Lima C, Blazer D, Teri L, Brodaty H, Livingston G, World Federation of Biological Psychiatry - Old Age Taskforce: Systematic review of the effectiveness of non-pharmacological interventions to improve quality of life of people with dementia. Int Psychogeriatr 2012;24:856-870.

7 Desai AK, Schwartz L, Grossberg GT: Behavioral disturbance in dementia. Curr Psychiatry Rep 2012;14:298309.

8 Woods RT: Reality orientation and staff attention: a controlled study. Br J Psychiatry 1979;34:502-507.

-9 Bach D, Bach M, Böhmer F, Frühwald T, Grilc B: Reactivating occupational therapy: a method to improve cognitive performance in geriatric patients. Age Ageing 1995;24:222-226.

$\checkmark 10$ Breuil V, De Rotrou J, Forette F, Tortrat D, Ganansia-Ganem A, Frambourt A, Moulin F, Boller F: Cognitive stimulation of patients with dementia: preliminary results. Int J Geriatr Psychiatry 1994;9:211-217.

$>11$ Spector A, Thorgrimsen L, Woods B, Royan L, Davies S, Butterworth M, Orrell M: Efficacy of an evidence-based cognitive stimulation therapy programme for people with dementia. Br J Psychiatry 2003;183:248-254.

-12 Spector A, Orrell M, Woods B: Cognitive Stimulation Therapy (CST): effects on different areas of cognitive function for people with dementia. Int J Geriatr Psychiatry 2010;25:1253-1258.

13 Takeda M, Tanaka T, Okochi M, Kazui H: Non-pharmacological intervention for dementia patients. Psychiatry Clin Neurosci 2012;66:1-7.

14 Jelcic N, Cagnin A, Meneghello F, Turolla A, Ermani M, Dam M: Effects of lexical-semantic treatment on memory in early Alzheimer disease: an observer-blinded randomized controlled trial. Neurorehabil Neural Repair 2012;26:949-956.

15 Han P, Kwan M, Chen D, Yusoff SZ, Chionh HL, Goh J, Yap P: A controlled naturalistic study on a weekly music therapy and activity program on disruptive and depressive behaviors in dementia. Dement Geriatr Cogn Disord 2010;30:540-546.

-16 Teri L, Logsdon RG, Peskind E, Raskind M, Weiner MF, Tractenberg RE, Foster NL, Schneider LS, Sano M, Whitehouse P, Tariot P, Mellow AM, Auchus AP, Grundman M, Thomas RG, Schafer K, Thal LJ, Alzheimer's Disease Cooperative Study: Treatment of agitation in AD. A randomized, placebo-controlled clinical trial. Neurology 2000;55:1271-1278.

17 Gormley N, Lyons D, Howard R: Behavioural management of aggression in dementia: a randomized controlled trial. Age Ageing 2001;30:141-145.

18 Bourgeois MS, Schulz R, Burgio L, Beach S: Skills training for spouses of patients with Alzheimer's disease: outcomes of an intervention study. J Clin Geropsychol 2002;8:53-73.

-19 Teri L, Gibbons LE, McCurry SM, Logsdon RG, Buchner DM, Barlow WE, Kukull WA, LaCroix AZ, McCormick W, Larson EB: Exercise plus behavioral management in patients with Alzheimer disease: a randomized controlled trial. JAMA 2003;290:2015-2022.

20 Teri L, McCurry SM, Logsdon R, Gibbons LE: Training community consultants to help family members improve dementia care: a randomized controlled trial. Gerontologist 2005;45:802-811.

-21 Chapman SB, Weiner MF, Rackley A, Hynan LS, Zientz J: Effects of cognitive communication stimulation for Alzheimer's disease patients treated with donepezil. J Speech Lang Hear Res 2004;47:1149-1164.

22 Olazarán J, Muñiz, R, Reisberg B, Peña-Casanova, del Ser T, Cruz-Jentoft AJ, Serrano P, Navarro E, García de la Rocha ML, Frank A, Galiano M, Fernández-Bullido Y, Serra JA, González-Salvador MT, Sevilla C: Benefits of cognitive-motor intervention in MCI and mild to moderate Alzheimer disease. Neurology 2004;63:23482353.

23 Mittelman MS, Haley WE, Clay OJ, Roth DL: Improving caregiver well-being delays nursing home placement of patients with Alzheimer disease. Neurology 2006;67:1592-1599.

24 Chien W, Lee Y: A disease management program for families of persons in Hong Kong with dementia. Psychiatr Serv 2008;59:433-436.

25 Gates NJ, Sachdev PS, Fiatarone Singh MA, Valenzuela M: Cognitive and memory training in adults at risk of dementia: a systematic review. BMC Geriatr 2011;11:55-69.

26 Olazarán J, Reisberg B, Clare L, Cruz I, Peña-Casanova J, Del Ser T, Woods B, Beck C, Auer S, Lai C, Spector A, Fazio S, Bond J, Kivipelto M, Brodaty H, Rojo JM, Collins H, Teri L, Mittelman M, Orrell M, Feldman HH, Muñiz R: Nonpharmacological therapies in Alzheimer's disease: a systematic review of efficacy. Dement Geriatr Cogn Disord 2010;30:161-178. 
27 Morris JC: The Clinical Dementia Rating (CDR): current version and scoring rules. Neurology 1993;43:24122414.

28 Folstein MF, Folstein SE, McHugh PR: Mini-mental state: a practical method for grading the cognitive state of patients for the clinician. J Psychiatr Res 1975;12:189-198.

29 American Psychiatric Association: Diagnostic and Statistical Manual of Mental Disorders, ed 4, revised. Washington, American Psychiatric Association, 2000.

30 Mondini S, Mapelli D, Vestri A, Arcara G, Bisiacchi PS: Esame neuropsicologico breve 2. Milano, Raffaello Cortina, 2011.

-31 Katz S, Downs TS, Cash HR, Grotz RC: Progress in development of index of ADL. Gerontologist 1980;1:20-30.

-32 Reisberg B, Auer SR, Monteiro IM: Behavioral pathology in Alzheimer's disease (BEHAVE-AD) rating scale. Int Psychogeriatr 1997;8:301-308.

33 Yesavage JA, Brink TL, Rose TL, Lum 0, Huang V, Adey MB, Leirer VO: Development and validation of a geriatric depression screening scale: a preliminary report. J Psychiatr Res 1983;17:37-49.

34 Bergamaschi S, Iannizzi P, Mondini S, Mapelli D: 100 esercizi di stimolazione cognitiva. Milano, Raffello Cortina, 2008.

35 Orrell M, Woods B, Spector A: Should we use individual cognitive stimulation therapy to improve cognitive function in people with dementia? BMJ 2012;344:e633.

-36 Fernàndez M, Gobartt AL, Balaña M, the COOPERA Study Group: Behavioural symptoms in patients with Alzheimer's disease and their association with cognitive impairment. BMC Neurol 2010;10-87.

37 Burns A, Jacoby R, Levy R: Psychiatric phenomena in Alzheimer's disease. 4. Disorders of behaviour. Br J Psychiatry 1990;157:86-94.

-38 Kumar A, Koss E, Metzler D, Moore A, Friedland RP: Behavioural symptomatology in dementia of the Alzheimer type. Alzheimer Dis Assoc Disord 1988;2:363-365. 